\title{
Oral Administration as an Effective Accommodation for Students with ADHD
}

\author{
Kaitlynn Penner \\ Florida International University
}

\begin{abstract}
Attention-deficit/hyperactivity disorder (ADHD) is a widespread disorder among young children, shown to affect up to $9 \%$ of the population (Sinha, Sagar, Mehta, 2008). It is a behavioral disorder that predominantly affects executive functions. Executive functioning encompasses anything that relates to the mental controls that permit humans to solve problems, plan, and behave appropriately [1]. Tasks such as time management, attending to a speaker, organization, planning, acting appropriately for the environment, and shifting focus all fall into this category. The definition of ADHD encompasses a spectrum of problems that can include difficulty paying attention, impulsivity, and hyperactivity. This opposes the definition of executive functioning, making room for profound deficits in one or more of these functions. Though much information is known about executive functioning skills, there has been less investigation in regards to its effects on test taking. This study investigated the effects of oral administration of assessments for students identified with ADHD. The purpose was to determine the results of oral administration of math assessments in comparison to normal administration for this population of students. It also looked to compare the difference in effects of this form of testing at two different grade levels.
\end{abstract}

\section{Introduction}

There have been numerous studies done regarding strategies, accommodations, and modifications for effective programs for students with Attention Deficit Hyperactivity Disorder (ADHD). Many of these include teaching strategy deviations, assignment and assessment modifications, and environmental alterations. The effectiveness of each of these varies from child to child. These strategies must be individualized based on a number of factors including gender, grade level, and behaviors [2]. In saying that, there are definite strategies that have been repeatedly proven successful to a more generalized population of learners.

In our education system assessments are the number one indicator of student success. As students matriculate through various levels of schooling, the importance of assessment success only grows. For those pupils who struggle with test anxiety and other problems associated with testing, their success can be stalled. For educators of students with ADHD, it is crucial that the most effective testing strategies be used in order to create a motivating environment geared toward achievement.

The four factors that create issues with taking assessments are: attention and focus, distractibility and switching/shifting, time management, and perception [3]. As stated previously, ADHD causes difficulties with executive functioning, making it hard to retrieve learned information. It is important to understand these things in order to identify which strategies to pursue in part of the student's academic plan. This research was based on the voices of undergraduate level students who have been diagnosed with ADHD. This portrayal of student needs can prove to be very useful to practitioners, as these students are able to pin point the strategies that work for them.

\section{Commonly Used Accommodations}

Frequent breaks, movement, the use of timers and alarms, and extended time are all notable strategies to be used during testing for students with ADHD [3]. Exploring all of these ideas is important to ensure student success. The aforementioned in addition to others can help with focus and time management, two of the major concerns associated with ADHD. 
Though all approaches may not work for every student, these have been backed by prior research and are involved in further exploration in this area.

A frequent break is a strategy that has been used for various types of disabilities, including ADHD, Autism Spectrum Disorders (ASD), and Specific Learning Disabilities (SLD). The idea of this is to ensure that for a short amount of time, information is being comprehended or recalled effectively. Its shortterm purpose is to avoid loss of focus, which can lead to long-term lack of motivation and lower test scores. This applies to how the student studies for the test, as well as how they take it. Allowing for movement during a break can increase its effectiveness. Rest periods can be used to move around and get the blood flowing, allowing expenditure of extra energy prior to having to regain complete focus [2].

The use of timers and alarms, most notably used with students with Autism Spectrum Disorders as a method of priming, can also be used for students with ADHD. In conjunction with frequent breaks, this is used to monitor the test-taking time (on time) and the break time (off time) in the "time on-time off" approach recommended by many practitioners [3]. It provides a way for both the student and the instructor to have an idea of when these on and off times will occur. Timers also permit more independence for the student, providing more intrinsic motivation and naturalistically teaching the ability to self-monitor.

When it comes to extended time in terms of students with ADHD, it can be a catch 22. Extra time is most often needed to render the most accurate results of student knowledge, however it can encourage more distraction time and less work time. Educators need to understand the purpose and correct utilization of this in order to use it to benefit the student. In concurrence with the aforementioned strategies it can prove to be very effective. Used in the appropriate way, "Students with ADHD said extended time was used to give them more time to focus or take a break as a result of difficulty maintaining attention, distractibility, executive functioning issues, the need to move around, selfmonitor time, or a combination of these" [3] p. 112. This perception was taken from college level students who have been living with ADHD all of their academic lives. Students in elementary, middle, and high school, who may lack this self-awareness will need to be monitored more closely by educators in order to ensure that the extra time allotted is being used to their benefit and not to their disadvantage.
Modifying the delivery of tests may prove to be the best option, however not always the easiest. Due to executive functioning difficulties, students with ADHD may be able to perform better on oral tests, through portfolios, or oral reports [4]. In addition use of color, large fonts, bold lettering to draw attention to crucial aspects of tasks [5] or questions can be helpful for students on written assessments. It forces students to focus on that word or group of words that is highlighted or in bold lettering. It draws attention to the task at hand, providing more guidance to ensure student understanding.

In regards to the environment, and more holistic approaches in strategies for students with ADHD, creating an environment that is engaging enough, while not being distracting can be a challenging task. It should be engaging and motivating in the presented material, while eliminating the distractibility factors through preferential seating and dividers. In the action research completed by Greenewald and Walsh "assigned seating at separate desks [was] used for independent written work and carrels were provided for students who felt dividers would improve their ability to concentrate" [6] pg. 4. This study, in addition to the use of other strategies (charts, light signals, and verbal and written directions), rendered great results. In comparison to baseline, where nonattending behavior was shown on average eight times per class period, after the intervention, it was decreased to just two times per period.

In relation to test taking, preferential seating and dividers can be employed for the use of students with ADHD and with all students for that matter. Seating should be away from any distraction, students should be seated an appropriate distance away from each other, and dividers or folders can be used to limit disruptions.

Though not as common, the use of brain games in order to stimulate students with ADHD has been proven to be beneficial to classroom engagement and executive functioning [7]. As discussed in research completed by Wegrzyn et al, ADHD is caused by problems in the brain's prefrontal cortex [8], [9], [10], [11]. This study has proven that brain games have the ability to engage this area of the brain to counteract this dysfunction.

Finally, and perhaps the most obvious strategy is to familiarize the students with those strategies and accommodations that are provided for them, leading to an improvement in test scores [12]. Providing a student with all of the resources is great, but without knowledge of their purpose and their most effective 
mode of use, they cannot properly do their job. Familiarizing them with strategies and why and how they are helpful will help them long term and for the big picture.

\section{Oral Administration}

In regards more specifically to mathematics, a significant research point is the need for the oral administration of tests, especially those with multiple choice or word problems. The reason for its importance lies behind three main points. These include (1) mathematics tests often require students to have extensive reading skills, (2) there is a strong correlation between multiple-choice math assessments and reading assessments, (3) because of Individuals with Disabilities Education Act of 1997 and No Child Left Behind, students with disabilities are mandated to participate in standardized testing [13]. The main focus of this research of Tindal and Ketterlin-Geller (2004) revolves around eliminating reading as an access skill. Access skills, meaning it is a perquisite skill to the ability to show their mastery of other skills and knowledge, often in other content areas. Reading is the biggest access skill for students with disabilities, which poses a major problem to educators in content areas such as history, science, and mathematics.

In addition to this fact, another studied demonstrated how oral administration of math tests affected middle level students with and without learning disabilities. The study revealed that there was an improvement in test scores for both populations of students [14]. This generalized increase in scores across diverse learners can indicate numerous things. First, it points to the fact that this accommodation benefits a larger population than those students with disabilities, also showing that reading levels prove to be a hindrance to lots of students. Secondly, it shows that this accommodation can allow for a more accurate representation of mathematic knowledge than that of standard administration. Further information needs to be researched in regards to this accommodation and students diagnosed with ADHD.

\section{Discussion}

Despite the abundance of research revolving around testing accommodations, in comparison, there is little regarding the oral administration of assessments. Although scholars have researched this topic, it has been in regards mostly to the oral administration of high-stakes testing for students with learning disabilities. In saying this, it has proven to be a typical accommodation for these kinds of tests, but does not always find it's way into the classroom for curriculum based assessments. This makes the research available very crucial for the implication of future research, indicating that it is an area that needs to be further addressed.

Based on the literature reviewed, it can be concluded that there are many research-based accommodations that can be appropriate for students with ADHD and various other disabilities. It is imperative that educators understand, however, that this review provides a large amount of suggested accommodations that have proven to work with the given population of students. However, all students with ADHD do not have the same behaviors and needs, and are not based on a one-size fit all model. Oral administration looks to have positive results, but based on previous research, and the future of this research, cannot be used for every student. However, the need in this area is evident and this specified accommodation has proven that it can be very useful for students with of this population.

\section{Methods}

This section includes information relating to the research questions, the selected participants, the exact intervention implemented, and the data collection measures.

\subsection{Research questions}

This study aimed to answer the following questions:

- Do orally administered math assessments lead to higher scores for students with ADHD?

- Do these results vary depending on grade level?

\subsection{Participants}

The participants of this study included two students diagnosed with ADHD. One student was in sixth grade and the other was in the second grade. The sixth grade student was male and the second grade student was female. 


\subsection{Intervention}

The intervention was oral administration of math assessments. The math problems were read aloud and the student wrote them down themselves before solving the problem. The problems were administered one at a time. The student completed each problem before being administered the next problem.

\subsection{Data Collection Procedures}

Data was collected through the use of the following instruments.

Data Source 1: Assessments. Before implementing the intervention the student's scores were evaluated on all the math assessments taken to date (during the current school year). Theses tests were used as pretests, prior to the start of the accommodation. Three assessments were re administered using oral administration. These were considered the post-tests, after the beginning of the intervention. These assessment scores helped to determine to what extent the intervention was in fact successful, if at all.

Data Source 2: Observation. A direct observation of a normal administration of an assessment and one of an oral administration of an assessment were conducted for anecdotal purpose.

Data Source 3: Interview/Survey. The student was asked a series of survey questions before the start of the intervention. This included questions regarding their feelings on math, as well as assessments and specific strategies. The students were given the same survey at the conclusion of the research. The students were also interviewed at the conclusion of the project about how they liked the intervention and their views on its success.

\section{Findings}

\subsection{Assessment Data}

Table 1 and Figure 1 show the assessment scores pre intervention and using the intervention for one, sixth grade student. These results were consistent with the hypothesis that math assessments administered orally to students with ADHD would improve their scores. Though the first assessment elicited the same score with both types of administration, assessment two and three showed dramatic increases. The student showed a $21 \%$ increase on the second assessment and a $26 \%$ increase on the third assessment with the use of oral administration, as shown below.

Table 1. Sixth grade math assessment scores

\begin{tabular}{|c|c|c|}
\hline & $\begin{array}{c}\text { Standard } \\
\text { Administration }\end{array}$ & $\begin{array}{c}\text { Oral } \\
\text { Administration }\end{array}$ \\
\hline Assessment \#1 & $33 \%$ & $33 \%$ \\
\hline Assessment \#2 & $42 \%$ & $63 \%$ \\
\hline Assessment \#3 & $38 \%$ & $63 \%$ \\
\hline
\end{tabular}

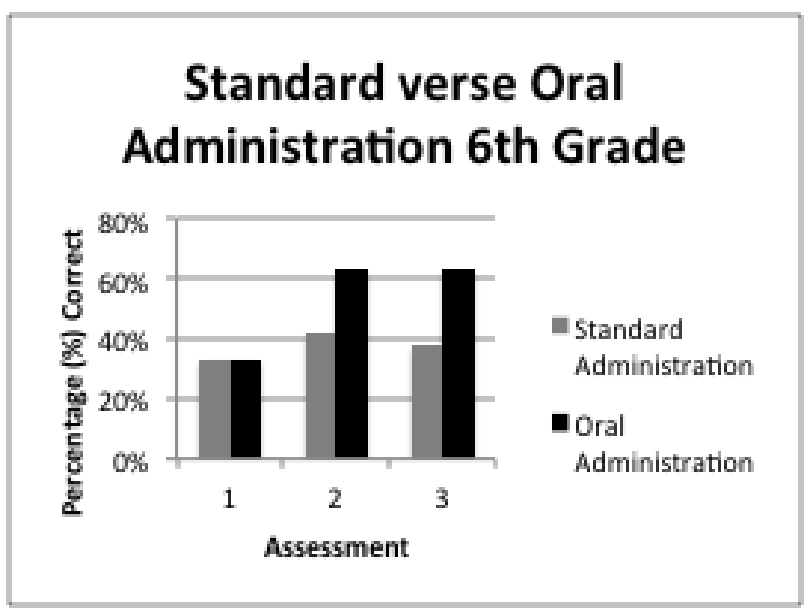

Figure 1. Sixth grade comparison of \% correct of standard administration and oral administration

The results revealed in Table 2 and Figure 2 show the math assessment results of the student with ADHD in the second grade using first standard administration and second oral administration. These demonstrated less significant positive results. There was no change in the first assessment scores. The second assessment actually revealed a decrease. Because of this decrease, the third assessment used was a perfect score to determine if in fact there would be a pattern of decrease with the intervention. However, there was no change in the third and final assessment. 
Table 2. Second grade math assessment scores

\begin{tabular}{|c|c|c|}
\hline & $\begin{array}{c}\text { Standard } \\
\text { Administration }\end{array}$ & $\begin{array}{c}\text { Oral } \\
\text { Administration }\end{array}$ \\
\hline Assessment \#1 & $85 \%$ & $85 \%$ \\
\hline Assessment \#2 & $90 \%$ & $86 \%$ \\
\hline Assessment \#3 & $100 \%$ & $100 \%$ \\
\hline
\end{tabular}

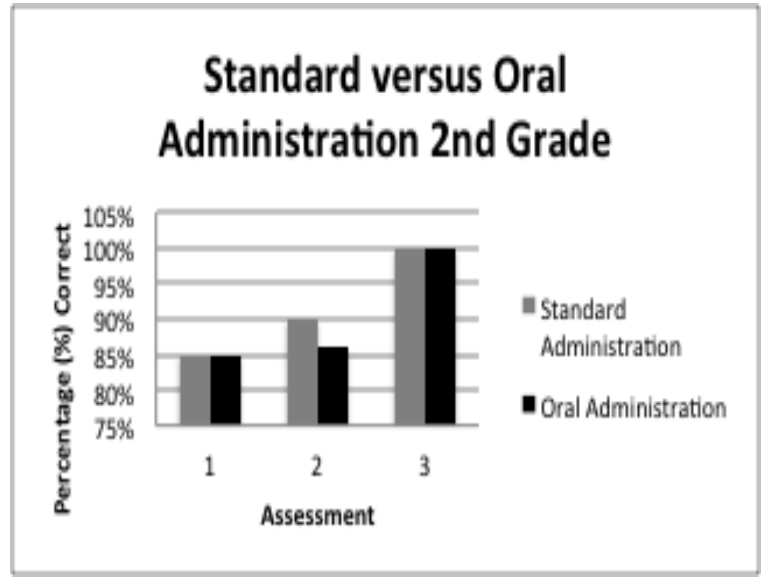

Figure 2. Second grade comparison of percentage (\%) correct of standard administration and oral administration

Figure 3 shows the $\%$ increase or decrease of each assessment at each grade level. This demonstrates the effectiveness of the intervention directly compared between the two grade levels. It shows that in this case it was more effective at the sixth grade level. At the sixth grade level, the hypothesis that this intervention would be an effective way of increasing math scores for students with ADHD was proven correct. However, at the second grade level there was no change and even a very slight decrease with the use of the intervention.

There are a variety of reasons for the fact that no change was shown for the first assessment for the sixth grade student. In part, it was most likely due to the student needing to adjust and get used to the intervention. Once the intervention was used, the student was able to fully benefit from the verbal administration as shown by the data. In further analysis of these results, the greatest area of improvement from the pre test to the test utilizing the intervention was on the word problems. On assessment two, out of the three word problems, he got all three incorrect on the initial assessment. With oral administration, the student was able to correctly solve and answer two out of the three problems. This demonstrates that one reason for the increase in scores may at least in part be due to reading and reading comprehension difficulties. Explained in the research of Tindal and Ketterlin-Geller (2004), reading as an access skill can decrease student's scores in other content areas, such as this math assessment. Being able to hear the problem read aloud, allowed this student to bypass this skill and demonstrate his knowledge of mathematics [13].

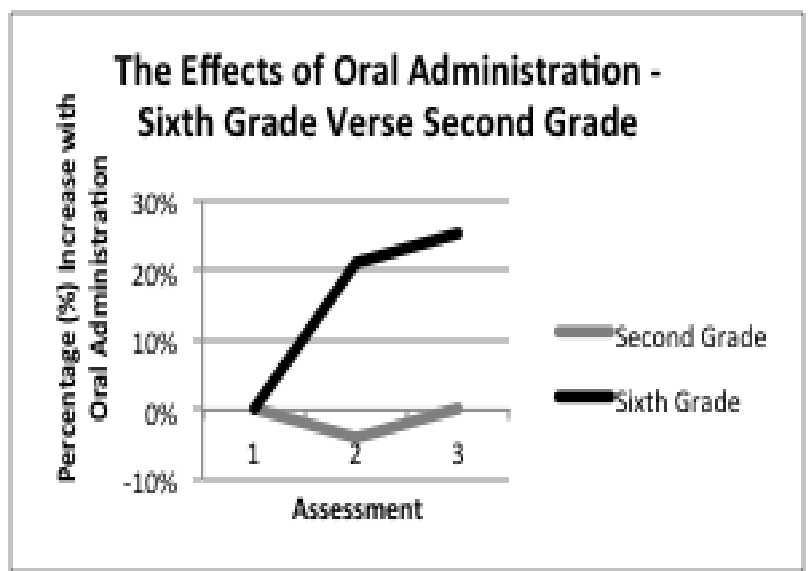

Figure 3. Comparison of Percentage (\%) Increase with the Intervention of sixth grade students and second grade student

Because there was no change, and a decrease in score for the second grader, it brings about questions as to why this case rendered such different results from the other student. The scores of this student subject were already at a much higher average than the previously mentioned student. In saying that, the student may not have needed the accommodation. Based on observation, the student appeared to be a very strong oral reader, eliminating the problem of reading difficulties as an interference of mathematic success. Because she read the problem aloud to herself, she may already be benefiting enough from this strategy and not need further oral intervention.

\subsection{Observation Data}

When observed taking a standard assessment in the classroom environment, the sixth grade student took longer than most students to finish the assessment. He got distracted between problems and needed prompting to focus on the assessment. However, 
when observed during the oral administration of an assessment, the student appeared calm and focused. He was observed using self-talk in a low voice to talk himself through the problems. This shows that the intervention allowed the student to focus and have the ability to talk through the problem aloud.

The behaviors observed of the second grade student subject during a standardly administered assessment included whispering, as she talked her way through the problems. The student was the first one finished and upon completion, she appeared anxious as demonstrated by nail biting. During the observation of an orally administered assessment, the student used the same self-talk strategy to talk out solving the problems, this time in a louder voice. After being read the problem, she also read it aloud herself. She showed very strong oral reading skills for a student her age. In addition, though easily distracted before the test, she was able to focus on the test and seemed anxious just to get through it. She wrote the problems all over the paper and didn't number them, showing disorganization. When prompted she numbered the problems, however she numbered them incorrectly.

Based on this observation it can be concluded that the intervention could have been unsuccessful in this case due to this lack of organization. Because the student wrote the problem down herself, there was no set order of where to write the problems. For this student, structure is needed to make up for lack of organization and this could have been where the intervention failed. In saying that oral administration may still be beneficial to this student, however the protocol and the way that it is administered may have to be changed. Additional accommodations should be made to improve the organization of this individual.

\subsection{Pre and Post Intervention Student Questionnaire}

The results of the student questionnaire are presented in Table 3 and Table 4.

Table 3. Student Questionnaire - Sixth grade

\begin{tabular}{|c|c|c|}
\hline Statement & $\begin{array}{c}\text { Pre Intervention } \\
\text { Response }\end{array}$ & $\begin{array}{c}\text { Post } \\
\text { Intervention } \\
\text { Response }\end{array}$ \\
\hline I like math. & Some of the time. & Some of the time. \\
\hline $\begin{array}{c}\text { I am good at } \\
\text { math. }\end{array}$ & $\begin{array}{c}\text { Some of the } \\
\text { time. }\end{array}$ & $\begin{array}{c}\text { Some of the } \\
\text { time. }\end{array}$ \\
\hline Math makes me & None of the & Some of the \\
\hline
\end{tabular}

\begin{tabular}{|c|c|c|}
\hline $\begin{array}{c}\text { frustrated with } \\
\text { myself. }\end{array}$ & time. & time. \\
\hline $\begin{array}{c}\text { Seeing that I } \\
\text { have a lot of } \\
\text { math problems } \\
\text { to do makes me } \\
\text { frustrated. }\end{array}$ & $\begin{array}{c}\text { Some of the } \\
\text { time. }\end{array}$ & $\begin{array}{c}\text { Some of the } \\
\text { time. }\end{array}$ \\
\hline $\begin{array}{c}\text { Talking out } \\
\text { loud helps me } \\
\text { solve math } \\
\text { problems. }\end{array}$ & $\begin{array}{c}\text { Some of the } \\
\text { time. }\end{array}$ & $\begin{array}{c}\text { Some of the } \\
\text { time. }\end{array}$ \\
\hline $\begin{array}{c}\text { Hearing the } \\
\text { math problems } \\
\text { spoken out loud } \\
\text { helps me solve } \\
\text { them. }\end{array}$ & $\begin{array}{c}\text { Some of the } \\
\text { time. }\end{array}$ & $\begin{array}{c}\text { Some of the } \\
\text { time. }\end{array}$ \\
\hline
\end{tabular}

Table 4. Student Questionnaire - Second grade

\begin{tabular}{|c|c|c|}
\hline Statement & $\begin{array}{c}\text { Pre Intervention } \\
\text { Response }\end{array}$ & $\begin{array}{c}\text { Post } \\
\text { Intervention } \\
\text { Response }\end{array}$ \\
\hline I like math. & Some of the time. & Some of the time. \\
\hline $\begin{array}{c}\text { I am good at } \\
\text { math. }\end{array}$ & All of the time. & All of the time. \\
\hline $\begin{array}{c}\text { Math makes me } \\
\text { frustrated with } \\
\text { myself. }\end{array}$ & $\begin{array}{c}\text { Some of the } \\
\text { time. }\end{array}$ & $\begin{array}{c}\text { Some of the } \\
\text { time. }\end{array}$ \\
\hline $\begin{array}{c}\text { Seeing that I } \\
\text { have a lot of } \\
\text { math problems } \\
\text { to do makes me } \\
\text { frustrated. }\end{array}$ & $\begin{array}{c}\text { Some of the } \\
\text { time. }\end{array}$ & $\begin{array}{c}\text { Some of the } \\
\text { time. }\end{array}$ \\
\hline $\begin{array}{c}\text { Talking out } \\
\text { loud helps me } \\
\text { solve math } \\
\text { problems. }\end{array}$ & $\begin{array}{c}\text { None of the } \\
\text { time. }\end{array}$ & $\begin{array}{c}\text { None of the } \\
\text { time. }\end{array}$ \\
\hline $\begin{array}{c}\text { Hearing the } \\
\text { math problems } \\
\text { spoken out loud } \\
\text { helps me solve } \\
\text { them. }\end{array}$ & $\begin{array}{c}\text { Some of the } \\
\text { time. }\end{array}$ & $\begin{array}{c}\text { Some of the } \\
\text { time. }\end{array}$ \\
\hline
\end{tabular}

For each question the students were asked to circle a. none of the time, b. some of the time, or c. all of the time. Table 3 shows the answers selected by the sixth grade student with ADHD pre and post intervention. It shows that there was very little change in the responses. The only thing that changed was that the student put that math made them frustrated some of the time on the post intervention survey as opposed to 
none of the time that was circled pre intervention. The rest of the answers remained the same on both.

Though the survey does not give a great picture of student needs, it shows a general feeling toward math and possible strategies that might help them. However, because the student selected some of the time for most answers on both surveys, it doesn't allow for exact feelings to be analyzed.

Table 4 shows the answers selected by the second grade student before the intervention and the answers chosen post oral administration intervention. It shows that the students answers post intervention were identical to the ones selected pre intervention. Overall, the answers show that the student has confidence in her math abilities and does not believe that verbally working through problems is a useful strategy for her. This opposes the observation data that showed that she utilized a great deal of self-talk to solve the problems on both assessments.

\subsection{Post Intervention Interview}

The interview questions posed to the students who underwent the intervention included 1) Does hearing math problems spoken aloud help you solve the problem? If so, explain why. 2) What strategies help you solve math problems best? 3) Do you think you did better on the tests where you were orally read the questions or the one that you read to yourself? This was an oral interview and the answers were recorded verbatim of what each student said. Table 5 shows both students' answers.

The findings of the oral interview were interesting in the fact that they did not back the quantitative assessment data. In fact it showed the opposite. While the second grade student did not prove to benefit from the oral administration, she stated that she thought that she did better on these assessments, due to the fact that otherwise she might skip problems. This shows that she is aware to some extent of the disorganization analyzed during the observational sessions. However, the sixth grade student who did benefit from the testing accommodation said that he thought that he did better on the tests that were administered in the standard manner. These points to the fact that often times elementary and middle school aged children may not know what strategies work best for them. It is the job of the educators and other professionals that work with these students to understand what strategies to implement to allow them to succeed.
Table 5. Post Intervention Interview

\begin{tabular}{|c|c|c|}
\hline $\begin{array}{c}\text { 1. Does hearing } \\
\text { math problems } \\
\text { spoken aloud } \\
\text { help you solve } \\
\text { the problem? If } \\
\text { so, explain why. } \\
\text { Student }\end{array}$ & $\begin{array}{c}\text { "Sometimes } \\
\text { because if its } \\
\text { easy I can do it } \\
\text { in my head. } \\
\text { Otherwise I } \\
\text { read it over and } \\
\text { over again." }\end{array}$ & $\begin{array}{c}\text { "Student } \\
\text { time but mostly } \\
\text { I do them in my } \\
\text { head." }\end{array}$ \\
$\begin{array}{c}\text { 2. What } \\
\text { strategies help } \\
\text { you solve math } \\
\text { problems best? }\end{array}$ & $\begin{array}{c}\text { "Fingers and } \\
\text { memorization" }\end{array}$ & "Borrowing" \\
\hline $\begin{array}{c}\text { 3. Do you think } \\
\text { you did better } \\
\text { on the tests } \\
\text { where you were } \\
\text { orally read the } \\
\text { questions or the } \\
\text { one that you } \\
\text { read to } \\
\text { yourself? }\end{array}$ & $\begin{array}{c}\text { "The one I read } \\
\text { myself." }\end{array}$ & $\begin{array}{c}\text { "When it was } \\
\text { read to me } \\
\text { because }\end{array}$ \\
& & $\begin{array}{c}\text { otherwise I miss } \\
\text { it or skip it." }\end{array}$ \\
\hline \multicolumn{2}{|c|}{} & \\
\hline
\end{tabular}

\section{Limitations}

There are several limitations of this study that should be highlighted. Namely, the most significant limitation was the sample size. There was only one student identified with ADHD in both classes chosen to investigate. In saying that, the research is a comparison of two single case $\mathrm{AB}$ designed experiments. For future studies, larger sample sizes would be beneficial to further prove the implications of oral administration of math assessments for students with ADHD at various grade levels. In addition, the results could be further justified by using an ABA design in order to further prove the intervention was in fact the reason for the sudden increased test scores of the sixth grade student subject. Another limitation is the length of time of the intervention. The intervention was only done over a two-week period. This was due to a variety of unforeseen circumstances, including having to change the school site that the intervention was conducted in.

\section{Implications}

Oral administration of math assessments can increase student scores for those students with ADHD. 
Though these results were not shown at the second grade level, for the sixth grade student the intervention was very beneficial. At a local level, the findings of this research conclude that this intervention should be continued with this particular student. Continuing to implement this type of intervention in the future for this student, as well as others with ADHD will only continue to render positive results. Once the students become accustomed to the intervention, the results will only improve. Because every student is different, this intervention cannot be proven useful for all students with ADHD. In addition, it should be used with other proven testing accommodations and modifications. These in addition to oral administration can yield higher overall test scores. In saying that, further research on this topic needs to be done. Other grade levels and larger sample sizes should be further investigated. This study has demonstrated that this intervention can be an effective accommodation for students with ADHD, however in order to prove generalization to a larger population of students, further research needs to be pursued.

\section{References}

[1] Sinha, P., Sagar, R., \& Mehta, M. (2008). Executive Function in Attention Deficit/Hyperactivity Disorder. J. Indian Association Child Adolescent Mental Health, 4(2), 44-49.

[2] Reiber, C., \& McLaughlin, T. (2004). Classroom Interventions: Methods to Improve Academic Performance and Classroom Behavior for Students with AttentionDeficit/Hyperactivity Disorder. The International Journal of Special Education, 19(1).

[3] Ofiesh, N., Moniz, E., \& Bisagno, J. (2015). Practice Brief: Voices of University Students with ADHD About Test-taking: Behaviors, Needs, and Strategies. Journal of Postsecondary Education and Disability, 28(1).

[4] Soleil, G. (1995). ADHD - Building Academic Success. Policy Brief.

[5] Carbone, E. (2001). Arranging the classroom with an eye (and ear) to students with ADHD. Teaching Exceptional Children, 34(2), 72-81

[6] Greenwald, M., \& Walsh, C. (1996). "The Effect of Environmental Accommodations on attending Behavior of an ADHD chapter 1 Student: An action research study" Paper presented at the Annual Meeting of an American Educational Research Association. New York, NY. April 816.
[7] Wegrzyn, S., Hearrington, D., Martin, T., \& Randolph, A. (2012). Brain Games as a Potential Nonpharmaceutical Alternative for the Treatment of ADHD. Journal of Research on Technology in Education, 107-130. Retrieved November 12, 2015.

[8] Barkley, R.A. (1997). Behavioral inhibition, sustained attention, and executive functions: Constructing a unifying theory of ADHD. Psychological Bulletin, 121(1), 65.

[9] Brennan, A. R., \& Arnsten, A. F. T. (2008). Neuronal mechanism underlying attention deficit hyperactivity disorder. Annals of the New York Academy of Sciences, 1129, 236-245.

[10] Dickstein, S.G., Bannon, K., Xavier Castellanos, F., \& Milham, M. P. (2006). The neural correlates of attention deficit hyperactivity disorder: An ALE metaanalysis. Journal of Child Psychology \& Psychiatry, 47(10), 1051-1062.

[11] Dige, N., \& Wik, G. (2005). Adult attention deficit hyperactivity disorder identified by neuropsychological testing, International Journal of Neuroscience, 115(2), 169183.

[12] Miranda, Ana, Sonia Jarque, and Raul Tarraga. "Interventions in School Settings for Students With ADHD." Exceptionality (2006): 35-52. Print.

[13] Tindal, G., Ketterlin-Geller, L. R. (2004). Research on Mathematics TestAccommodations Relevant to NAEP Testing. Paper presented at NAGB Conference on Increasing the Participation of SD and LEP Students in NAEP.

[14] Elbaum, B. (2007). Effects of an Oral Testing Accommodation on the Mathematics Performance of Secondary Students With and Without Learning Disabilities. The Journal of Special Education, 40(4), 218-229. 